\title{
Monitoring of Plant Species and Communities on Coastal Cliffs: Is the Use of Unmanned Aerial Vehicles Suitable?
}

\author{
Sandro Strumia ${ }^{1, *(D)}$, Maurizio Buonanno ${ }^{2}$, Giovanna Aronne ${ }^{3}$, Antonio Santo ${ }^{4}$ and \\ Annalisa Santangelo 5 \\ 1 Department of Environmental, Biological and Pharmaceutical Sciences and Technologies, \\ University of Campania “Luigi Vanvitelli" Via Vivaldi, 43, 81100 Caserta, Italy \\ 2 Institute for Agricultural and Forest Systems in the Mediterranean, Italian National Research \\ Council (CNR-ISAFoM), via Patacca, 85, 80056 Ercolano, Italy; maurizio.buonanno@isafom.cnr.it \\ 3 Department of Agricultural Sciences, University of Naples Federico II, Via Università, 100, \\ 80055 Portici, Italy; aronne@unina.it \\ 4 Department of Civil, Architectural and Environmental Engineering, University of Naples Federico II, \\ via Claudio 21, 80125 Napoli, Italy; santo@unina.it \\ 5 Department of Biology, University of Naples Federico II, Via Foria, 223, 80139 Napoli, Italy; \\ santange@unina.it \\ * Correspondence: sandro.strumia@unicampania.it
}

Received: 28 January 2020; Accepted: 8 April 2020; Published: 10 April 2020

\begin{abstract}
Cliffs are reservoirs of biodiversity; therefore, many plant species and communities of inland and coastal cliffs are protected by Council Directive 92/43/EEC (European Economic Community), and their monitoring is mandatory in European Union countries. Surveying plants on coastal cliff by traditional methods is challenging and alternatives are needed. We tested the use of a small Unmanned Aerial Vehicle (UAV) as an alternative survey tool, gathering aerial images of cliffs at Palinuro Cape (Southern Italy). Four photo-interpreters analysed independently the derived orthomosaic and plotted data needed for the monitoring activity. Data showed to be not affected by photo-interpreters and reliable for the prescribed monitoring in the European Union (EU). Using the GIS analysis tools, we were able to: (a) recognise and map the plant species, (b) derive and measure the area of distribution on the cliff of habitat and species, and (c) count Eokochia saxicola individuals and gather quantitative data on their projected area. Quality of the images represented the main constraint, but incoming technological improvements of sensors and UAVs may overcome this problem. Overall results support the use of UAVs as an affordable and fast survey technique that can rapidly increase the number of studies on cliff habitats and improve ecological knowledge on their plant species and communities.
\end{abstract}

Keywords: Primula palinuri; Dianthus rupicola; chasmophytes; rocky habitat; plant mapping; census technique; drone; Habitat 1240; Habitat 8210

\section{Introduction}

Cliff plant species and communities have a remarkable scientific interest and their ecology and biogeography have been investigated across the world [1-5]. Several studies highlight that cliff habitats host many phylogenetic relicts and rare plant species in the Mediterranean region [2,6-9] and worldwide [3].

Cliffs, whether coastal or inland, are considered as climatic refugia because they shelter large endemic floras in most unglaciated areas of the world and large relict floras in areas where significant 
glaciation have occurred [10]. Cliffs represent the exclusive habitat for $35-40 \%$ of the plant species endemic to the alpine region of Europe [11] and for $66 \%$ of the endemics to New Zealand [12]. Such a concentration of plant diversity is generally related not only to environmental peculiarities of cliff habitats but also to the consideration that cliffs are some of the least human disturbed habitats [3]. Such habitats are considered to have offered a refuge from unfavourable climatic conditions, competition with hillside communities, and grazing [2] and, therefore, represent important sites for biodiversity conservation as well as plant population differentiation and species diversification.

Due to geomorphological characteristics of cliffs, acting as a physical barrier to main human activities, plant species and communities are not exposed to more common anthropogenic threats and pressure, except for those related to recreational activities (rock climbing) and alien plant species invasion. Conversely, a principal threat is represented by geological processes (landslides, erosion) and effects of global climate changes (rise of temperature, changes in precipitation regimes, sea level, wave exposure, and salt spray). Such factors make threatened with extinction several cliff plant species and communities, requiring political action for their conservation.

The Council Directive 92/43/EEC (European Economic Community), better known as Habitat Directive (hereafter HD), is considered the most powerful political instrument of European Union to preserve biodiversity. The art. (article) 11 of the Directive makes mandatory for the member states the monitoring of Habitat listed in Annex I and Plant Species listed in Annexes II of the HD (hereafter, HA1 and PSA2, respectively) to assess their conservation status over the time [13]. As reported in art. 1 of HD, the responsibility for conservation of both HA1 and PSA2 is higher if they are designated as "priority". Many cliff species are listed in the annexes of HD (e.g., Centranthus amazonum Fridl. and A.Raynal, Daphne petraea Leyb., Moehringia tommasinii Marches.) as well as some cliff habitats (e.g., 1230—Vegetated sea cliffs of the Atlantic and Baltic Coasts, 1240—Vegetated sea cliffs of the Mediterranean coasts with endemic Limonium spp. and 8210-Calcareous rocky slopes with chasmophytic vegetation). The presence of both HA1 and PSA2 makes mandatory to monitor most of the cliffs in the European Union. The Report format requires data regarding distribution, population size, extent of abiotic habitat, main pressure, and threats for the PSA2 and distribution, surface area, typical species, main pressure, and threats for HA1. All those data are necessary to evaluate the conservation status over time, based on surveys as complete as possible [14], but several of them are still lacking for Italian plant species [15]. Unfortunately, studies on plant communities of the cliffs are hardly achievable, mainly because of site inaccessibility [3]; this is more evident in the case of coastal cliff, often plugging directly into the sea.

In such conditions, conventional field sampling at the community level (e.g., permanent plots or transects), assuming the presence of the data collector close to rocky face, is challenging for safety reasons; moreover, the engagement of personnel with good expertise in climbing and rappelling techniques is required [4,16-23]. The use of climbing routes causes also a clear bias in the sampling design, due to the particular features (unbroken and dry faces with few or no crevices) needed to have feasible routes that could be not representative of the average conditions and vegetation cover of all the cliff $[18,20,23]$.

Verticality of cliff and steep rocky faces pose further problems. As highlighted by Goñi et al. [19] and Gigante et al. [24], the orthogonal projection of vertical surfaces used in conventional maps or orthomosaics brings some shortcomings, such as the underestimation of the total area.

To overcome the inaccessibility of such habitats, remote data collection by means of optical tools (i.e., binoculars, telescopes, telephoto lenses) is often used [25-27]. In case of long-term monitoring, the Fixed Point Photography (FPP) or Photo Point Monitoring (PPM) technique was used [28]; it consists in taking multitemporal terrestrial photographs of a site, from a fixed point ( $\mathrm{x}, \mathrm{y}, \mathrm{z}$ coordinates) and angle, using always the same lens focal length. An alternative approach based on oblique aerial photographs, derived from video imagery captured using a helicopter, was proposed by Barron et al. [16]. 
In the last 20 years Unmanned Aerial Vehicles (UAVs), commonly referred to as drones, have been successfully applied to monitor plant communities for ecological research and for conservation and applicative purposes, but their use regards only horizontal plant communities [29-35]. On the other hand, for many years, UAVs and digital photogrammetry software have been successfully applied to assess and monitor geological risk in steep slope rocky cliffs [36-40]. The solution to draw detailed thematic and geometrically reliable maps of steep slope cliffs by acquisition of accurate oblique and horizontal photographs can be potentially applied in the field of plant science as well.

In this paper, we present the results of a research activity carried out on a coastal cliff of the Palinuro Cape peninsula (Cilento, Southern Italy), plugging directly into the sea and hosting both HA1 and PSA2 [41]. The research aimed to (a) test the effectiveness of using UAVs and Geographic Information System (GIS) to gather qualitative and quantitative data useful to monitor cliff plants and habitats according to HD; (b) assess the impact of different photo-interpreters on the accuracy and repeatability of such data, which represents a critical issue in monitoring [42]. Additional GIS elaborations were also performed as a trial to get further ecological features of the studied plants.

\section{Materials and Methods}

\subsection{Study Area}

Palinuro Cape $\left(40^{\circ} 01^{\prime} 40^{\prime \prime} \mathrm{N}, 15^{\circ} 16^{\prime} 45^{\prime \prime} \mathrm{E}\right)$ is located along the southern coast of Cilento (Campania region, south Italy) in the Cilento, Vallo di Diano and Alburni National Park (CVDANP), the second largest Nature Park in Italy and very relevant for the richness of natural and cultural heritage of its territory. Palinuro Cape is made up by Mesozoic carbonates (dolomitic limestones) and is characterized by the presence of several plunging cliffs up to one hundred meters high. Joints, bedding planes and faults influence cliff morphology, and lateral changes in lithology result in changes in the coastal shape: the presence of weaker formations (damage zones or highly fractured limestones) allows the formation of little bays and beaches [43].

Palinuro Cape cliffs and rocky shores host typical plant communities composed by aerohaline chasmophytes, or by more or less closed aerohaline grassland (Crithmo-Staticetalia Molinier 1934; Corine Biotopes 18.2; Eunis B3.3), mentioned in the revised Annex I of Resolution 4 (1996) of the Bern Convention on endangered natural habitats types (https://eunis.eea.europa.eu/habitats/46\#legal). Moreover, those plant communities encompass the HA1 1240-Vegetated sea cliffs of the Mediterranean coasts with endemic Limonium spp. Due to their elevation, cliffs and rocky shores host patches of plant communities typical of inland cliffs (Dianthion rupicolae Brullo and Marcenò 1979; Corine Biotopes 62.1; Eunis H3.2), encompassing the HA1 8310—calcareous rocky slopes with chasmophytic vegetation. On this cliff, together with the typical and widespread species, such as Crithmum maritimum L., Daucus carota L., Limbarda crithmoides (L.) Dumort, also endemic or extremely rare species such as Primula palinuri Petagna, Dianthus rupicola Biv. subsp. (subspecies) rupicola (both PSA2), Limonium remotispiculum (Lacaita) Pignatti, Centaurea cineraria L. subsp. cineraria are present [43]. The recent finding on the same cliffs of two locations of Eokochia saxicola (Guss.) Freitag and G. Kadereit [41], one of the rarest species of Mediterranean flora [2,44] and PSA2 designated as "priority" species, confirms the relevant biogeographic and conservation importance of Palinuro Cape. Because of the presence of very interesting vegetation types, with rare plants species, it was formerly included in the Important Plant Area (IPA) "M. Bulgheria e Capo Palinuro" [45] and in Natura 2000 Network (Site Capo Palinuro-IT8050008), as Special Area of Conservation (SAC). In this respect, the monitoring of both species and habitat is mandatory for the Management Authority (art. 11 of HD), and the results should be used for the reporting activities under art. 17 of the same Directive.

The area selected for the research activities is a mainly north facing cliff plugging directly into the sea, about $200 \mathrm{~m}$ in length and up to $70 \mathrm{~m}$ a.m.s.l (above mean sea level), not accessible by mainland without rappelling technique. It was selected because it hosts three PSA2 (one of them with "priority 
status") and two HA1. This cliff, thus, represents an interesting study site, as on the same surface both monitoring of the habitat and of the species of HD annexes can be performed.

\subsection{Target Species}

Target species of this work are those from the PSA2 and the typical/diagnostic species of HA1 (therefore, indicating their presence) [46]. Hereafter, general information about the selected species is reported: distribution [47,48], life forms [44], recommended observation time for monitoring [25,49], mention in international legal instruments, conservation status according to reporting under art. 17 for PSA2 [50], IUCN (International Union for Conservation of Nature) ranking [51-53], and monitoring mandatory under art. 11 of HD for the species and/or its Habitat.

\section{Eokochia saxicola (Guss.) Freitag and G. Kadereit}

Distribution: endemic to S Italian peninsula, recorded only in six localities in the southern Campania region and in Sicily, only on the little island of Strombolicchio.

Life form: Chamaephyte / Nano-Phanerophyte

Observation time: October

Annex I (Dir. 92/43/EEC) Habitat: 1240

Conservation Status ex art. 17 HD: unfavourable-inadequate (U1)

IUCN ranking: Endangered (EN)

Legal instruments: Berna Convention (Annex 4); Dir. 92/43/EEC (Annex II, IV—priority species)

Monitoring: mandatory both for species and habitat

Primula palinuri Petagna

Distribution: endemic to S Italian peninsula (Campania, Basilicata and Calabria region)

Life form: Geophyte / Hemicryptophyte

Observation time: January-March

Annex I (Dir. 92/43/EEC) Habitat: 8210

Conservation Status ex art. 17 HD: unfavourable-inadequate (U1)

IUCN ranking: Vulnerable (VU)

Legal instruments: Berna Convention (Annex 4); Dir. 92/43/EEC (Annex II, IV)

Monitoring: mandatory both for species and Habitat

Dianthus rupicola Biv. subsp. rupicola

Distribution: Mallorca, Spain, Tunisia; S Italian peninsula (Campania, Basilicata and Calabria region) and Sicily.

Life form: Chamaephyte

Observation time: June-September

Annex I (Dir. 92/43/EEC) Habitat: 8210 (typical species)

Conservation Status ex art. 17 HD: Favourable (FV)

UCN ranking: Least Concern (LC)

Legal instruments: Berna Convention (Annex 4); Dir. 92/43/EEC (Annex II, IV)

Monitoring: mandatory both for species and Habitat

Crithmum maritimum L.

Distribution: widespread along the cost of Mediterranean Sea and on the Atlantic coast of Europe and Morocco.

Life form: Chamaephyte

Observation time: April-June

Annex I (Dir. 92/43/EEC) Habitat: 1240 (typical species)

IUCN ranking: Least Concern (LC)

Legal instruments: none

Monitoring: mandatory only for Habitat

Limonium remotispiculum (Lacaita) Pignatti

Distribution: endemic to S Italian peninsula (Campania, Basilicata and Calabria region). 
Life form: Chamaephyte

Observation time: April-June

Annex I (Dir. 92/43/EEC) Habitat: 1240 (typical species)

IUCN ranking: Least Concern (LC)

Legal instruments: none

Monitoring: mandatory only for Habitat

\subsection{UAV Aerial Survey: Planning and Execution}

The flight was performed on October 2015. The time of the year for the aerial survey was chosen considering the phenology of the species to be mapped (e.g., flowering, fruiting, or leafing), with regard to the most threatened species, E. saxicola. Due to the difficulty to detect this species [41], the time of monitoring activities was chosen according to its best observation time, as reported in Ercole et al. [25]. Further, particular attention was paid to the weather forecast in order to have the right conditions to sail, to land at the base of the cliff, and to pilot the UAV to take images (i.e., lack of wind, low sea waves, height, and overcast sky conditions). Flight authorization were previously obtained from the CVDANP. To check the final resolution of the images and the accuracy of the measurements, appropriate targets were distributed before the flight at the bottom of the cliff in the only accessible area. More specifically, four USAF (United States Air Force)-1951 Resolving Power targets, ranging from group of elements 0 to 5 [54], and seven Ground Control Point (GCP) targets (two $20 \times 20 \mathrm{~cm}$ and five $30 \times 30 \mathrm{~cm}$ ). The distance between two of the five GCP targets was surveyed using a measuring tape to check the scale of the final orthomosaic.

UAV took-off and landed from a boat in front of the cliff, at about $50 \mathrm{~m}$ far away from the coast; the boat was not fixed by anchor to allow moving according to the UAV pilot needs. On the first boat, one botanist was boarded together with the engineer in charge of the flight. On the second boat, the other three botanists involved in the research were boarded to take additional photos, as further support in the following plant identification procedure.

The UAV used was a DJI "Inspire 1" multicopter with a DJI Zenmuse X3-FC350 gimbal camera with a small format Sony sensor $\left(1 / 2.3^{\prime \prime}-12.4 \mathrm{Mpx}\right)$ and a short focal length lens $(\mathrm{f}=3.6 \mathrm{~mm})$. The camera was setup in Auto Exposure mode and ISO 1600. The UAV was manually piloted to evenly space hovering points to ensure sufficient side and forward image overlap. The choice of a manual flight instead of an automatic one was mandatory, due to the risk of losing a sufficient Global Navigation Satellite System (GNSS) coverage when flying close to the vertical cliff, consequently causing loss of control of the UAV.

Two sets of horizontal images were taken parallel to the cliff at about 40 and $20 \mathrm{~m}$; both the first and the second set covered the whole survey area. A third set of photos was taken at $20 \mathrm{~m}$ with the optical axis of the camera facing downwards at about $45^{\circ}$ to reduce as much as possible "no-data holes" in the final 3D model, and to catch plants growing in rock depressions.

The entire data set $(40 \mathrm{~m}, 20 \mathrm{~m}$, and oblique images) in JPEG format was orthorectified and mosaicked using Agisoft Photoscan (now Metashape), a well-known structure from motion (SfM) software.

\subsection{Plant Species Identification, Mapping, and Biometry of the Main Target Species}

The orthomosaic (Figure 1) was imported in a GIS software (QGIS v.2.18) to proceed with (a) target plant species photointerpretation and mapping, (b) plotting the outline of E. saxicola, and finally (c) GIS analysis of species and community distribution maps.

The boundary of the cliff portion representing the area to be analysed (Total Surface, hereafter TS) was outlined and saved as polygon and its area was calculated. The region inside the Total Surface polygon was analysed independently by four botanists with different backgrounds: (a) plant taxonomy, (b) reproductive biology, (c) photointerpretation and GIS analysis, and (d) plant community field sampling, photointerpretation, and mapping. 
Plant identification represented the first step of the overall work. Each botanist photo-interpreted the orthomosaic. They identified and marked with a point all individual plant compiling point distribution maps of the five target species. At this step, additional photos taken by the botanists using a camera equipped with telephoto lenses were also used.

Afterwards, each botanist first labelled with sequential numbers each E. saxicola individual and then manually digitized the contour of each of them as accurate as possible, using the same approach of Getzin et al. [55]; the obtained shapefiles (geospatial vector data format) were used to calculate the area of the polygons. This work session was repeated five times. To avoid any systematic error, each botanist took a 2 to $4 \mathrm{~h}$ rest period between two sessions. No instructions were given concerning the order of polygon drawing.

\subsection{GIS Spatial Analysis}

The distribution maps were used to perform spatial operations on plant distribution by means of ordinary GIS tools.

First, using the module of vector geometry available in QGIS (convex hulls) the distribution maps of the five target species were used to assess the surface of abiotic habitat available for PSA2 and surface area of HA1. Therefore, the Area of Distribution on the Cliff (AODC) of each PSA2, or a combination of them (typical of HA1), was assessed.

Finally, the surface of the resulting polygons was measured and the map overlay procedures (intersections) were performed in order to assess main spatial relationships between the species. Moreover, the point distribution maps were used to perform topological analysis computing the proximity of individuals to sea level.

\subsection{Statistical Analysis}

Data of the area of E. saxicola polygons produced by GIS analysis were imported in a Microsoft Excel spreadsheet. According to definitions of Sokal and Rohlf [56] in our experimental design we considered:

- statistical population: totality of the individuals living on the analysed cliff and identified by all botanists;

- $\quad$ sampling unit: one individual;

- sample: a collection of individuals randomly selected within the sampling universe;

- variable: the area of each polygon;

- measurement: a single value of area.

In this respect, in our experimental design, each sampling unit has five measurements for each botanist.

The descriptive statistics were used to assess the main characteristics of the data; their normality was checked, and if asymmetry of data arose, the logarithmic transformation of data procedure was applied to obtain the normality [56], in order to use parametric inferential statistics.

Due to the presence of repeated measurements in our experimental design, a two-level nested ANOVA [56] was performed to assess the magnitude of variance for each source of variation. In our study case, the source of variation considered were:

- Among groups (botanists), it is the variance among polygons measured by different botanists due to a potential difference in measuring polygons.

- Among subgroups within groups, where a subgroup is a sample of randomly selected polygons measured by the same botanist; it is the variance between plants measured by the same data collector.

- Within subgroups. It is the variance within each plant polygon (error; between measurements of each polygon). 


\section{Results}

\subsection{Orthomosaic: Geometric Accuracy and Resolving Power}

The orthomosaic resulting from the post-processing procedure and the targets used to check the accuracy of image scaling and the final Resolving Power are showed in Figure 1. The field survey distance between the two reference GCP targets was $29.98 \mathrm{~m}$, while that measured on the orthomosaic was $30.37 \mathrm{~m}$. Therefore, we considered the dimensional accuracy of the orthomosaic compatible with the purpose of the monitoring task.

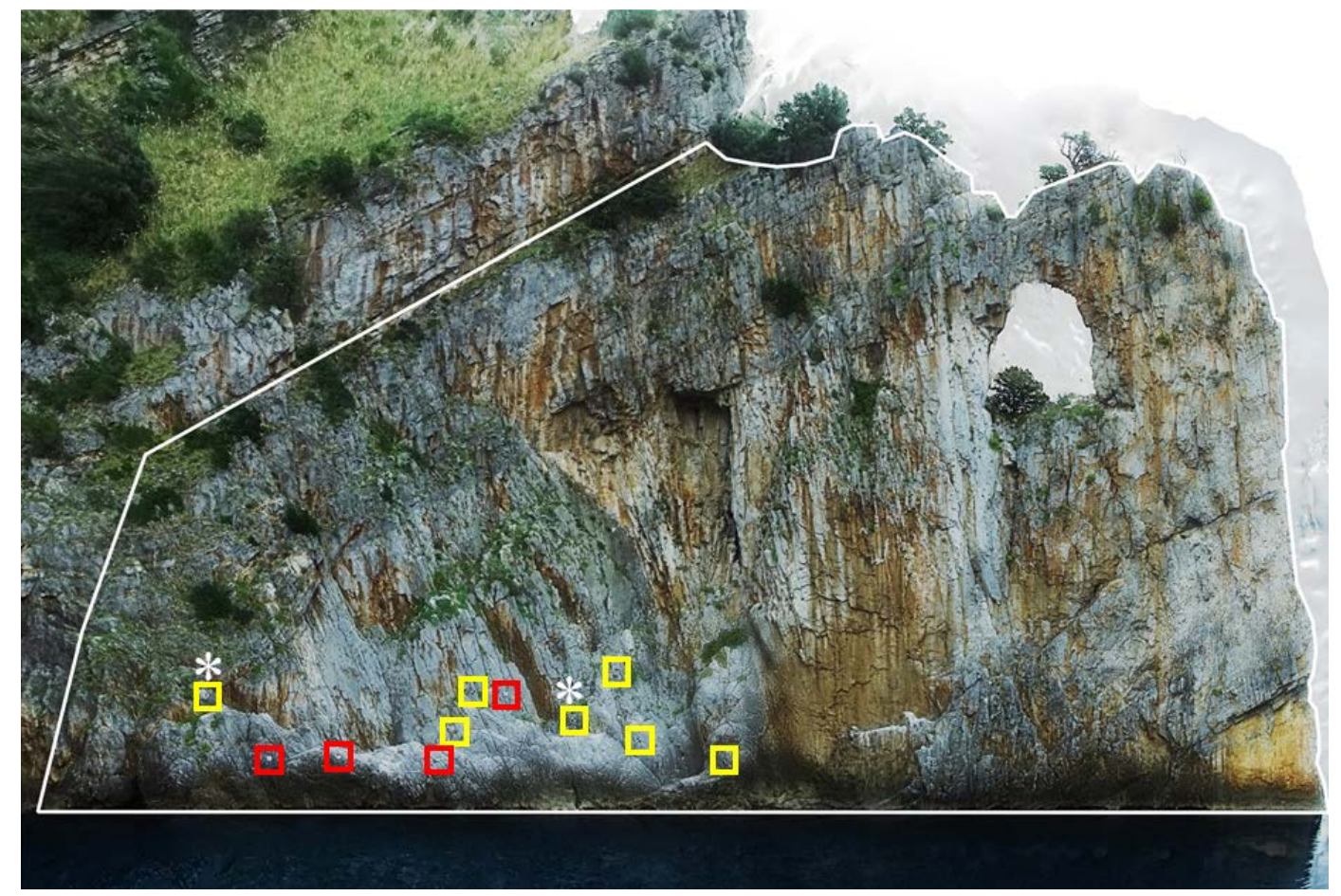

Figure 1. Orthomosaic of the analysed cliff. The Total Surface (TS) of the cliff is delimited by a white line. At the bottom of the cliff, the seven Ground Control Point (GCP) targets and the four USAF (United States Air Force)-1951 Resolving Power targets are highlighted by yellow and red squares respectively. The two asterisks indicate the GCPs used for checking image scaling.

Observing the USAF-1951 Resolving Power targets, the smallest element clearly visible was the fourth of Group 5. Consequently, the estimated resolving power of the orthomosaic, expressed as Line pair per mm, was $0.044 \mathrm{lp} / \mathrm{mm}$, whereas the fourth element width was $11.31 \mathrm{~mm}$, not so different from the theoretical Ground Sampling Distance (GSD) calculated for the DJI X3-F350 camera at $20 \mathrm{~m}$ from the subject (i.e., GSD = $8.75 \mathrm{~mm}$ ).

\subsection{Plant Species Identification}

All photo-interpreters identified the five selected plant species in the orthomosaic. Three of the five selected species were easily identified, but some differences between the species arose in the reliability of identification of some individual plants, due to their morphology and/or phenological stage at the moment of the flight. The main target species, Eokochia saxicola, resulted as easy to identify because of the phenological stadium (fruiting) at the moment of the image acquisition: the fruits were numerous and gave the plant a distinctive overall look, avoiding any confusion with other plant species with similar vegetative morphological features (i.e., Limbarda crithmoides (L.) Dumort) living on the same cliff, also very close to E. saxicola. Primula palinuri was also easily identifiable, although it was not in bloom and, therefore, without its distinctive yellow flowers. The typical large leaves and the 
slightly white colour of the fruiting inflorescence, due to the presence of a typical farinose deposit, helped the identification without the use of additional photos. Crithmum maritimum resulted as very easy to identify thanks to its enduring leaves and the presence of big inflorescence, lasting longer than the flowering and fruiting period and, therefore, very distinctive at the flight time. The identification of the other two species needed the use of additional photos taken from the boat to rule out uncertainties. The comparison between target species distribution maps produced by the four photo-interpreters pointed out some misidentifications in the case of Limonium remotispiculum due to the transparency of the plant profile. In fact, this entity has very small leaves forming a basal rosette browning in the summer and a very thin stem with apical inflorescence, very loose, and with small flowers.

The plotting of the identified plants allowed to produce five distinct distribution maps, each stored in a GIS file. The overlay of the five maps is showed in Figure 2.

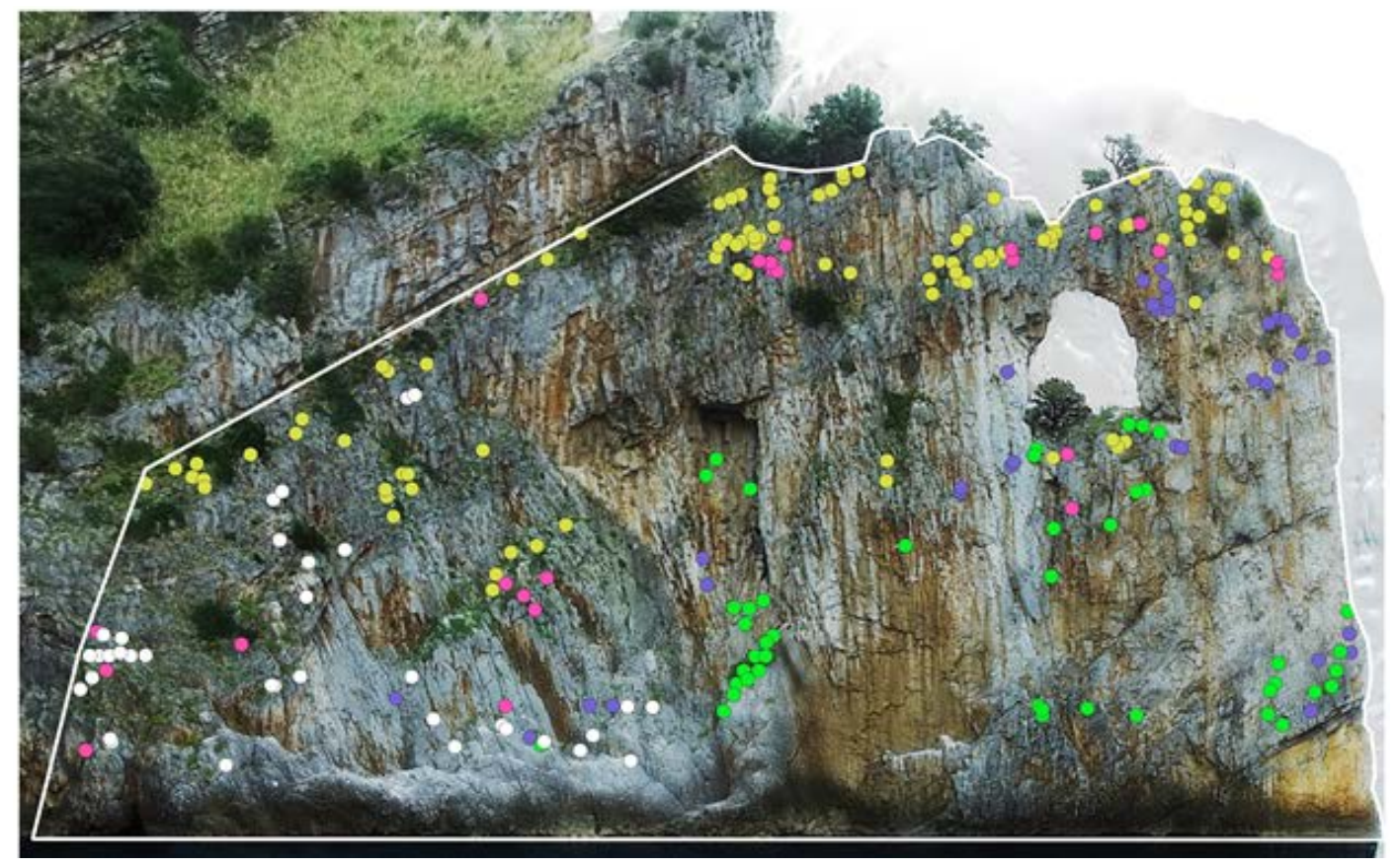

Figure 2. Overall distribution map reporting the position (dots) of each individual of the target species: Eokochia saxicola (green), Primula palinuri (yellow), Crithmum maritimum (white), Limonium remotispiculum (violet), Dianthus rupicola (pink). The white line represents the boundary of the considered area.

In regards to E. saxicola, individuals were identified and labelled separately by the four data collectors. All data collectors agreed in the identification of the same 42 individuals/clusters of E. saxicola and only one data collector misidentified eight plants of other species. Concerning the 42 correctly identified individuals, two of them were considered as a cluster of two individuals instead of just a single individual by three out of the four data collectors; these clusters were excluded by statistical analysis on biometry to have the same statistical population for each botanist. According to these results, the statistical population was represented by 40 individuals. Four samples (one for each botanist) containing 10 individuals randomly selected were assessed. The absence of the same individual within different samples was ensured.

\subsection{Analysis of the Plant Species Distribution}

The application of the convex hull method to the distribution maps of the PSA2 produced different polygons, representing the AODC and their areas, were assessed. The TS of the cliff section was $4741.8 \mathrm{~m}^{2}$ and was used to calculate the relative percentage of occupancy of the AODC of each species. The species with the highest AODC value (Figure 3) resulted D. rupicola $\left(2199.8 \mathrm{~m}^{2}\right)$ followed in descending order by P. palinuri $\left(1787 \mathrm{~m}^{2}\right)$, and E. saxicola $\left(1220 \mathrm{~m}^{2}\right)$. 


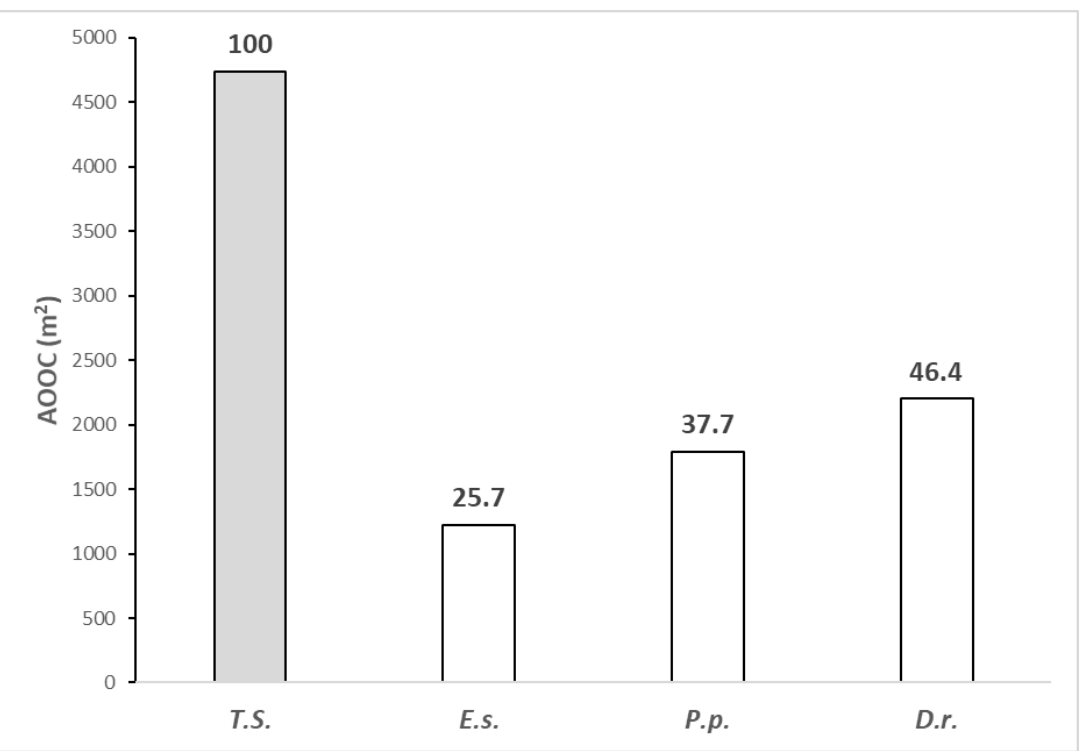

Figure 3. Area Of Distribution on the Cliff (AODC) $\left(\mathrm{m}^{2}\right)$ of the Total Surface area (grey bar) and of plant species of Annex II; E.s. = Eokochia saxicola, P.p. = Primula palinuri, D.r. = Dianthus rupicola . The value above each bar represent the percentage of the AODC of the species referred to the total considered area.

To evidence the potential contribution of the use of the orthomosaic to the analysis of the distribution pattern of the species on the same cliff, we analysed in GIS, by means of the intersect tool, the AODC of the two main species, in terms of both biogeography and conservation value, E. saxicola and P. palinuri. The two AODC resulted in overlapping for only $145 \mathrm{~m}^{2}$; this value represents $11.9 \%$ of the total surface occupied by P. palinuri and $6.5 \%$ of that occupied by E. saxicola, and highlights that the two species have a clearly separate distribution on the same cliff. The same result was appreciable also by visual analysis of the distribution map, if only the two species are selected (Figure 4); nevertheless, the use of GIS analysis allowed to quantify the value of the shared surface.

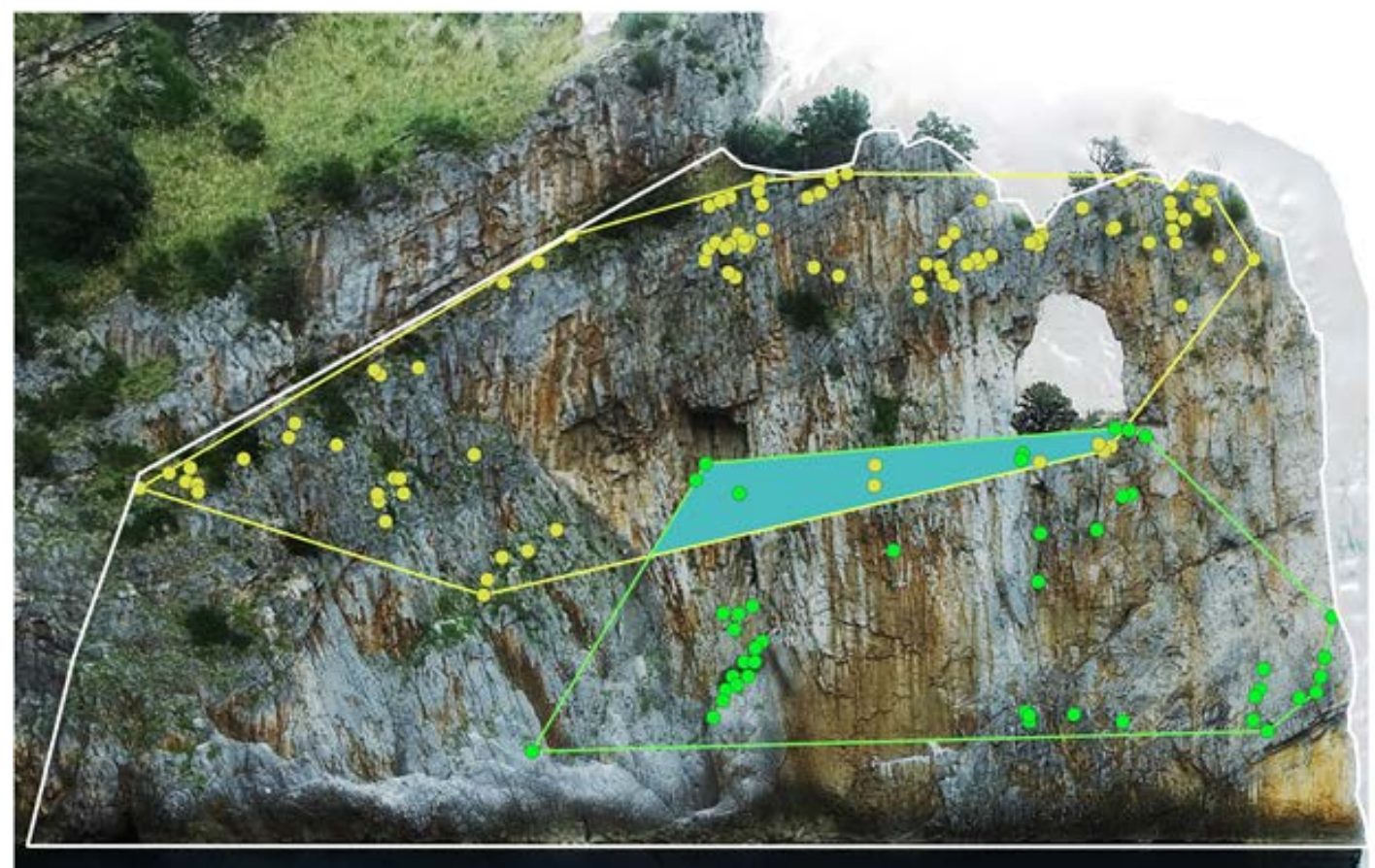

Figure 4. Distribution maps and Area Of Distribution on the Cliff of Eokochia saxicola (green) and Primula palinuri (yellow); in sea green, the overlap area between the two species. 
The point maps of these two species allowed to calculate the distance of each individual from the sea level. Data were processed with one-way-ANOVA and the result evidenced a very high statistical difference $(p<0.0001)$ between the average distance from sea level of P. palinuri $(43.35 \pm 9.64 \mathrm{~m}$ a.m.s.l.) and E. saxicola (18.54 $\pm 7.95 \mathrm{~m}$ a.m.s.1.). This confirms that the two species living on the same cliff have a separate distribution, with E. saxicola occupying the available spaces closer to the sea level.

\subsection{Analysis of Plant Community Distribution}

The distributions of the individuals of the species typical of the HA1 1240 (C. maritimum and $L$. remotispiculum) and 8310 (D. rupicola) were used to generate in GIS the polygons representing their AODC (Figure 5).

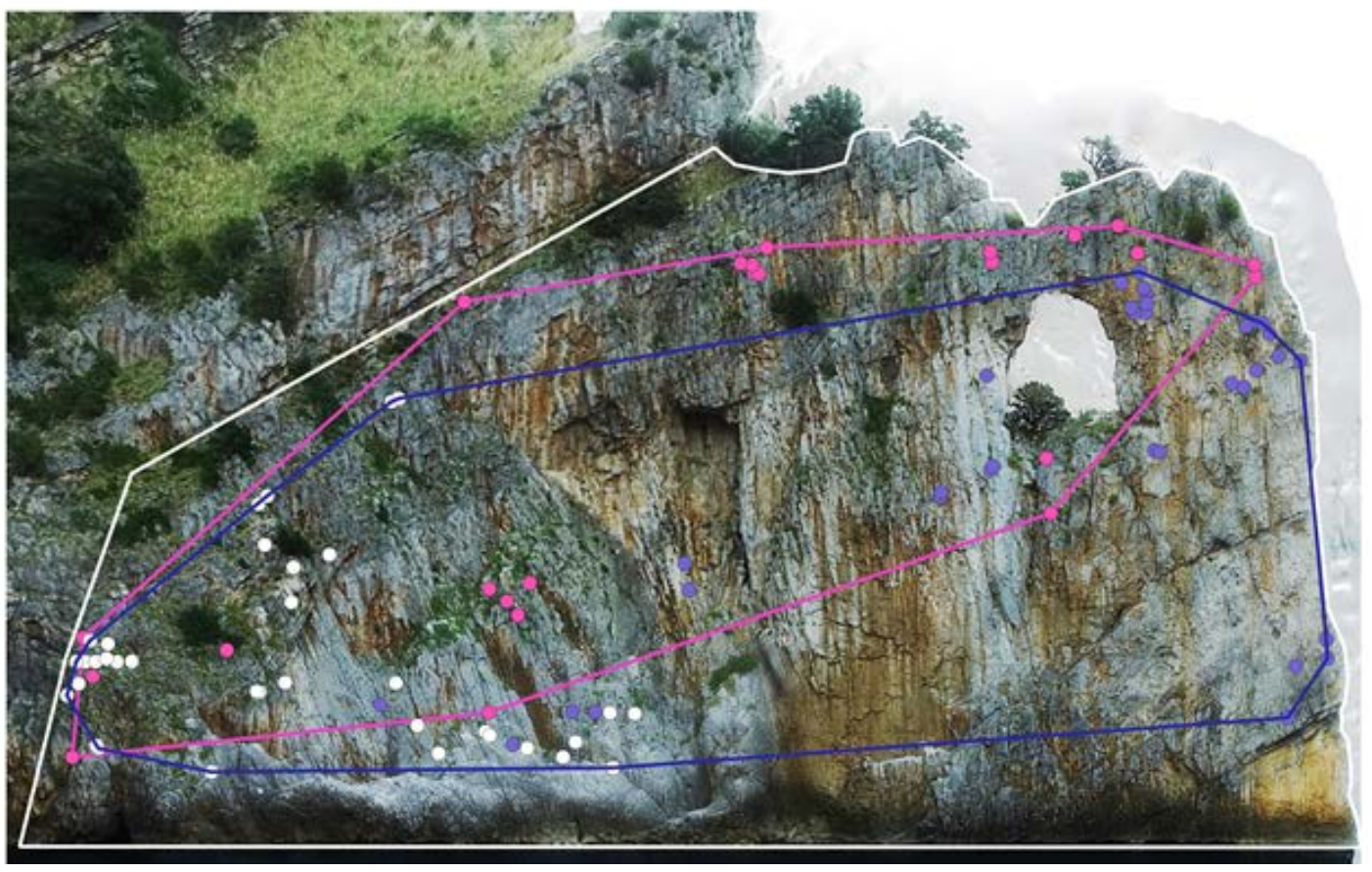

Figure 5. Distribution maps of the species typical of HA1 1240 (Crithmum maritimum, white dots, and Limonium remotispiculum, violet dots) and of HA1 8210 (Dianthus rupicola, pink dots) and Area of Distribution on the Cliff of the two habitats (blue line and pink line).

The AODC of HA1 1240 was $2936.5 \mathrm{~m}^{2}$ (61.9\% of the TS) and that of HA1 $83102199.8 \mathrm{~m}^{2}(46.4 \%$ of the TS). Moreover, the two polygons overlapped for $1768.8 \mathrm{~m}^{2}$ representing $60.2 \%$ of the 1240 entire surface and $80.4 \%$ of the entire 8310 surface.

\subsection{Biometry of Eokochia Saxicola}

According to the results of the two-level nested ANOVA (Table 1), there is a statistical difference between all the polygons representing plants on the cliff; this difference is not dependent by the four data collectors $(\mathrm{F}=3.85$; n.s.) but is due to the differences between individuals included in the same subgroup $(\mathrm{F}=73.07 ; p<0.001)$. These results indicate that no statistical differences arose between the four botanists having different skills; therefore, the used method was reliable in gather quantitative data on the surface of individuals living on the analysed cliff.

In the same table, it is possible to note that the lowest value of Mean Square (MS) resulted for the 'within' groups source of variation (that is error; between measurements of each polygon). Moreover, in the first one-way ANOVA, calculated in the preliminary analyses to perform the nested ANOVA, the differences between measurements were not statistically different (not shown). The absence 
of differences between measurements clearly indicates that all the botanists resulted homogeneous (precise) in plotting the polygons of the E. saxicola individuals.

Table 1. Nested ANOVA table, testing for the effect of botanists, polygons measured by the same botanist and error. SS, sum of squares; $d f$, degrees of freedom; $M S$, mean squares; F, F-ratio; Sig. significance level.

\begin{tabular}{cccccc}
\hline Source of Variation & SS & df & MS & F & Sig. \\
\hline $\begin{array}{c}\text { Among groups (botanists) } \\
\text { Among subgroups within groups }\end{array}$ & 0.25465 & 3 & 0.08488 & 3.848 & n.s. \\
$\begin{array}{c}\text { (among polygons measured by the same botanist) } \\
\text { Within subgroups }\end{array}$ & 11.76080 & 36 & 0.32669 & 73.074 & $* * *$ \\
$\begin{array}{c}\text { (error; between measurement of each polygon) } \\
\text { Total }\end{array}$ & 0.71530 & 160 & 0.00447 & & \\
\hline
\end{tabular}

\section{Discussion}

According to our sources, this was the first time that a UAV was used for a vegetation survey in such challenging conditions: (a) vertical or sub-vertical coastal cliff plunging directly into the sea; (b) use of a boat for UAV take-off and landing due to the absence of a close mainland; (c) manual flight due to insufficient GNSS coverage; (d) North facing slope affecting light intensity and, therefore, image quality. In such framework, the flight plan, as well as the characteristics and the setup of the camera mounted on the UAV, are crucial to obtain images clear enough to allow the first and essential step of the job: species identification.

Notwithstanding these environmental and technical constraints, our results demonstrated that images gathered using a UAV, and processed to generate an orthomosaic for photo-interpretation and GIS analyses, are effective in collecting qualitative and quantitative data on both plant species and communities of sea cliffs.

Four of the five target species (E. saxicola, P. palinuri, C. maritimum and D. rupicola) were easily detected without differences between the data collectors, even if the additional photos were helpful in identifying the species. Only L. remotispiculum resulted difficult to identify due to the small size of its rosette and inflorescence and the greyish colour of the leaves that lead it to "blend" with the rock in the background.

The distribution maps of the species allowed several GIS analyses, providing many quantitative data on AODC of plant species and communities. In this respect, the method resulted very reliable to gather data useful for monitoring purpose on both HA1 (population size, surface of abiotic habitat), and PSA2 (surface area) as requested by art. 11 and art. 17 of HD.

Moreover, the same GIS dataset potentially could be used as input data for many other spatial analyses, such as those aimed to identify relationships between species and environmental features. In this research, we easily used GIS analysis to get quantitative data on distribution patterns of the two main target species, E. saxicola and P. palinuri. Their AODC overlapped for a small area only, showing that the two species occupy two separate parts of the same cliff; this information is also consistent with the average distance from the sea level of the two species, because E.saxicola colonizes, preferentially, sectors of the cliff closer to sea level, whereas P.palinuri lives on higher ledges. These data are in accordance with those from literature concerning the biology/ecology of these two threatened species: E. saxicola has several morpho-physiological features typical of halophilous species [57], whereas $P$. palinuri is reported to be an endemic species, well adapted to the north-facing coastal Mediterranean cliffs $[58,59]$. Our results suggest that even if P. palinuri is reported as the only maritime species of the Primula genus [60], its distribution on the analysed cliff is restricted to the farthest areas from the sea.

The results of the research can be discussed also in terms of accuracy and precision of produced data on surface values of the main target species E. saxicola.

The inferential statistics indicated no statistical difference between the surfaces assessed by the four data collectors, proving that the methodology is reliable, even if the operators have no homogeneous 
background. The absence of statistical differences of repeated measurements within the same data collector indicate that the method allowed the precision of the measure. The method is, therefore, reliable to outline the perimeter of individual plants; thus, different personnel with different skills can confidently use it. These results confirm the effectiveness of the aerial images by UAV in obtaining detailed spatial metrics useful for monitoring actions in a cliff environment, as previously demonstrated for horizontal surface [55].

Even considering that our research was limited to one cliff only, there are clear evidences of major advantages in using this technique compared with the infield methods usually adopted to sample and/or monitor cliffs. The use of hiking routes to sample the chasmophytes plant communities imply that the data collectors must possess deep experience in rappelling and hiking technique in addition to their ability to identify, detect, and sample plant community features, narrowing the number of available people possessing all these skills. Moreover, the procedure of reducing the sampling surface to the narrow strips besides the hiking routes $[18,20,23]$ represents a potential bias affecting the gathered data due to the exclusive features of the rocky face selected for hiking purpose [61]. A further bias of such a procedure is that the surface "selected" for the sampling may result in not representative of the microsites hosting the plants

The use of optical tools as well as of Fixed Point Photography and/or Photo Point Monitoring [25, 26,28 ] has been suggested in the past in case of habitats inaccessible, but some limitation can be underlined on these methods due to perspective issues. In both methods, the point of observation is on the ground, at the base of the cliff, and usually not very far from it; consequently, regardless of the method of observation, there is clear bias due to the different distance of the same plant individuals living on the bottom or on the top of the cliff. This difference affects, negatively, the ability to identify a plant species or even to detect the presence of an individual if another plant lower on the cliff hides it. The orthomosaic produced with the UAV showed to overtake this problem.

As previously reported by Buonanno et al. [62], the clear limit that arose from our study case was represented by some features and setup of the camera, and by some features of the UAV itself that increased the difficulties in identifying plants on the cliff. Low photo images quality depends on a delicate equilibrium between several parameters, but three of them are crucial: shutter speed, aperture and ISO (intended as sensitivity of the image sensor). All these parameters influence the image quality, not only in terms of brightness but also in terms of contrast of depicted object. The topography and lighting conditions of the investigated site (a north-facing cliff) obviously increased the difficulty of taking photos, and the use of a UAV platform added further complexity to this starter matrix. In the selected cliff, the amount of light irradiance was deeply lower than in cliffs exposed to sun, and at the top of the cliff, the light conditions changed dramatically, turning into a backlit. Such amount of potential different light conditions made challenging to predict the better values of shutter speed, aperture and ISO. Indeed, low shutter speeds can generate blurred image effects whereas high ISO values bring "noisy" images. Therefore, a complete auto-mode shooting represents the best compromise and perhaps the unique way to take photos in these conditions. Considering the limits of the camera used in this research, we are confident that a higher quality camera will even avoid the use of additional images, improving the quality of acquired data.

The use of a UAV not equipped with frontal proximity sensors, and the risk of losing the GNSS signals when flying close to the vertical cliff, made mandatory the manual flight, and prevented taking photos closer to the cliff face. Such conditions had no effect on post-production processes, but affected negatively the species identification step of the job due to low quality of the images. The use of more performant equipment should overtake these problems. Nevertheless, at present, even if an automatic flight would sound the best choice, the local and unique geomorphological features of the cliff make the ability of the UAVS pilot a key factor. This is even more important if the UAV is used also to take close-up photos of the target plants as an alternative to using a telephoto lens from a swaying boat.

We want to emphasize that the orthomosaic gathered by drone freezes the analysed cliff status at the moment of sampling and, therefore, is suitable for monitoring $[29,63]$. Consequently, the same 
orthomosaic can be used at any time by other data collectors to extract new information or to check the previous photo-interpretation evidencing potential misinterpretations and/or weaknesses of previous research. In other words, the repeatability of photo-interpretation (the true "collecting data" phase), is an evident advantage over traditional field sampling where both plant identification and gathering of biometric data are not repeatable, especially on cliffs.

\section{Conclusions}

The maps obtained in this research could represent the baseline of monitoring actions that are mandatory for the EU member countries, according to art. 11 of HD. Periodic mapping of the same site could allow the assessment of changes over the time of plant density, distribution, and occupied surface. The methods used in our research allowed to sample, at the same time, both HA1 and PSA2 living on the same cliff, with an obvious advantage in terms of both time and money.

Moreover, this methodology could be applied, also, to analyse the main threats and pressure acting on cliff species and habitats (rock climbing, invasive alien plants, landslides), which could be easily checked by the analysis of the orthomosaic as well as possible effects of climate changes (e.g., sea level, wave exposure, and sea spray limit changes) on plant distribution.

Concerning the economic aspect of this research, we can specify that the flight alone costed about 2600 euros and the boats rent 300 euros; to these cost prices, it should be added the cost of the four botanists (shared between the field and laboratory activities), but we did not calculate the amount of hours spent in all the activities. In this contest, we underline that repeated photo-interpretation by the same operator has been used in our work only to assess the impact of different photo-interpreters on the accuracy and repeatability of final data. Such repetitions have not to be included in a standard protocol, not only for the potential bias due to a possible "learning curve", but also to avoid unnecessary extra costs in terms of time and money. Moreover, we would to highlight that in our research all the data collectors were botanists, even if with different skill. In case of personnel employed in local management authorities or nature parks, a training period is needed to gain a basic knowledge of the object (plant species and communities) of monitoring.

We trust that further and fast improvements in sensor and drone technology, coupled with survey cost reduction, will rapidly extend the methodology we have used to many other cliffs, allowing to gather data crucial for biodiversity conservation purposes. Increasing the available data on such interesting environments could fundamentally improve the knowledge on the ecology of their plant species and communities. This goal is even more crucial in the case of application of HD in Italy, due to the lack of knowledge for many species of flora of community interest [15].

Author Contributions: Conceptualization, S.S., G.A., M.B., A.S. (Antonio Santo), and A.S. (Annalisa Santangelo); data curation, S.S.; formal analysis, S.S.; funding acquisition, S.S.; investigation, S.S., G.A., M.B., and A.S. (Annalisa Santangelo); methodology, S.S., G.A., M.B., and A.S. (Annalisa Santangelo); project administration, A.S. (Antonio Santo), S.S.; resources, S.S., G.A., M.B., A.S. (Antonio Santo), and A.S. (Annalisa Santangelo); visualization, S.S., A.S. (Annalisa Santangelo); writing-original draft preparation, S.S., G.A., M.B., A.S. (Antonio Santo), and A.S. (Annalisa Santangelo). All authors have read and agreed to the published version of the manuscript.

Funding: This research and the APC was partially funded by a grant provided by Regione Campania-Direzione Generale per l'Ambiente e l'Ecosistema-Dip. 50 DG 06 U.O.D. 07.

Acknowledgments: We are extremely grateful to Mariella Danzi (Engineer, head of the Geofotogrammetrica S.r.l, via Gemito Vincenzo Napoli, Italy. Company) and Giuseppe Annunziata (UAV pilot) for their enthusiastic technical support. We thank the Cilento e Vallo di Diano Alburni National Park that authorized the flight. We are also grateful to the Palinuro Porto s.c.r.l. for logistic support. The authors are extremely grateful to four anonymous reviewers for their constructive criticism and helpful comments that improved the manuscript.

Conflicts of Interest: The authors declare no conflict of interest.

\section{References}

1. Bartlett, R.M.; Matthes-Sears, U.; Larson, D.W. Organization of the Niagara Escarpment cliff community. II. Characterization of the physical environment. Can. J. Botany 1990, 68, 1931-1941. [CrossRef] 
2. Davis, P.H. Cliff Vegetation in the Eastern Mediterranean. J. Ecol. 1951, 39, 63-93. [CrossRef]

3. Larson, D.W.; Matthes, U.; Kelly, P.E. Cliff Ecology: Pattern and Process in Cliff Ecosystems; Cambridge University Press: Cambridge, UK, 2000.

4. Kuntz, K.L.; Larson, D.W. Microtopographic control of vascular plant, bryophyte and lichen communities on cliff faces. Plant Ecol. 2006, 185, 239-253. [CrossRef]

5. Wilson, B.J.; Cullen, C. Coastal cliff vegetation of the Catlins region Otago, South Island, New Zealand. N. Z. J. Bot. 1986, 24, 567-574. [CrossRef]

6. Mifsud, S. Distribution of some rare or endemic chasmophytic and rupestral species growing along the coastal cliffs of the Maltese Islands. Webbia 2013, 68, 35-50. [CrossRef]

7. Soriano, P.; Estrelles, E.; Bianchelli, M.; Galiè, M.; Biondi, E. Conservation aspects for chasmophytic species: Phenological behavior and seed strategies of the Central Apennine threatened endemism Moehringia papulosa Bertol. Plant Biosyst. 2012, 146, 143-152. [CrossRef]

8. Sciandrello, S.; Guarino, R.; Minissale, P.; Spampinato, G. The endemic vascular flora of Peloritani Mountains (NE Sicily): Plant functional traits and phytogeographical relationships in the most isolated and fragmentary microplate of the Alpine orogeny. Plant Biosyst. 2014, 149, 838-854. [CrossRef]

9. Van der Maarel, E.; van der Maarel-Versluys, M. Distribution and conservation status of littoral vascular plant species along the European coasts. J. Coast. Conserv. 1996, 2, 73-92. [CrossRef]

10. Cooper, A. Plant species coexistence in cliff habitats. J. Biogeogr. 1997, 24, 483-494. [CrossRef]

11. Ellenberg, H. Vegetation Ecology of Central Europe; Cambridge Univ. Press: Cambridge, UK, 1988.

12. Wardle, P. Vegetation of New Zealand; Cambridge University Press: Cambridge, UK, 1991.

13. Henle, K.; Bauch, B.; Auliya, M.; Külvik, M.; Pe'er, G.; Schmeller, D.S.; Framstad, E. Priorities for biodiversity monitoring in Europe: A review of supranational policies and a novel scheme for integrative prioritization. Ecol. Indic. 2013, 33, 5-18. [CrossRef]

14. DG Environment. Reporting under Article 17 of the Habitats Directive: Explanatory Notes and Guidelines for the Period 2013-2018; Brussels, Belgium, 2017; Available online: http://cdr.eionet.europa.eu/help/habitats_art17/ index_html (accessed on 11 September 2019).

15. Fenu, G.; Bacchetta, G.; Giacanelli, V.; Gargano, D.; Montagnani, C.; Orsenigo, S.; Cogoni, D.; Rossi, G.; Conti, F.; Santangelo, A.; et al. Conserving plant diversity in Europe: Outcomes, criticisms and perspectives of the Habitats Directive application in Italy. Biodivers Conserv. 2017, 26, 309. [CrossRef]

16. Barron, S.J.; Delaney, A.; Perrin, P.M.; Martin, J.R.; O'Neill, F.H. National Survey and Assessment of the Conservation Status of Irish Sea Cliffs; Irish Wildlife Manuals; National Parks and Wildlife Service; Department of the Environment, Heritage and Local Government: Dublin, Ireland, 2011.

17. Clark, P.; Hessel, A. The effects of rock climbing on cliff-face vegetation. Appl. Veg. Sci. 2015, 18, 705-715. [CrossRef]

18. Farris, M.A. The effects of rock climbing on the vegetation of three Minnesota cliff systems. Can. J. Botany 1998, 76, 1981-1990.

19. Goñi, D.; Garcia, M.B.; Guzman, D. Métodos para el censo y seguimiento de plantas rupicolas amenazadas. Pirineos 2006, 161, 33-58. [CrossRef]

20. Kuntz, K.L.; Larson, D.W. Influences of microhabitat constraints and rock-climbing disturbance on cliff-face vegetation communities. Conserv. Biol. 2006, 20, 821-832. [CrossRef]

21. Lorite, J.; Serrano, F.; Lorenzo, A.; Cañadas, E.M.; Ballesteros, M.; Peñas, J. Rock climbing alters plant species composition, cover, and richness in Mediterranean limestone cliffs. PLoS ONE 2017, 12, e0182414. [CrossRef]

22. March-Salas, M.; Moreno-Moya, M.; Palomar, G.; Tejero-Ibarra, P.; Haeuser, E.; Pertierra, L.R. An innovative vegetation survey design in Mediterranean cliffs shows evidence of higher tolerance of specialized rock plants to rock climbing activity. Appl. Veg. Sci. 2018, 21, 289-297. [CrossRef]

23. Nuzzo, V.A. Effects of rock climbing on cliff goldenrod (Solidago sciaphila Steele) in northwest Illinois. Am. Midl. Nat. 1995, 33, 229-241. [CrossRef]

24. Gigante, D.; Attorre, F.; Venanzoni, R.; Acosta, A.T.R.; Agrillo, E.; Aleffi, M.; Alessi, N.; Allegrezza, M.; Angelini, P.; Angiolini, C.; et al. A methodological protocol for Annex I Habitats monitoring: The contribution of Vegetation science. Plant Sociol. 2016, 53, 77-87.

25. Ercole, S.; Giacanelli, V.; Bacchetta, G.; Fenu, G.; Genovesi, P. Manuali per Il Monitoraggio di Specie e Habitat di Interesse Comunitario (Direttiva 92/43/CEE) in Italia: Specie Vegetali; ISPRA, Serie Manuali e Linee Guida, 140/2016; Istituto Superiore Per la Ricerca Ambientale: Rome, Italy, 2016. 
26. Schmera, D.; Rusterholz, H.P.; Baur, A.; Baur, B. Intensity-dependent impact of sport climbing on vascular plants and land snails on limestone cliffs. Biol. Conserv. 2018, 224, 63-70. [CrossRef]

27. Alfaro-Saiz, E.; Granda, V.; Rodriguez, A.; Alonso-Redondo, R.; Garcìa-Gonzales, M.E. Optimal census method to estimate population sizes of species growing on rock walls: The case of mature Primula pedemontana. Glob. Ecol. Cons. 2019, 17, e00563. [CrossRef]

28. Joint Nature Conservation Committee (JNCC). Common Standards Monitoring Guidance for Maritime Cliff and Slope Habitats; Joint Nature Conservation Committee: Peterborough, UK, 2004.

29. Anderson, K.; Kevin, J.G. Lightweight unmanned aerial vehicles will revolutionize spatial ecology 2013. Front. Ecol. Environ. 2013, 11, 138-146. [CrossRef]

30. Baena, S.; Boyd, D.S.; Moat, J. UAVs in pursuit of plant conservation-Real world experiences. Ecol. Inform. 2018, 47, 2-9. [CrossRef]

31. Goncalves, J.; Henriques, R.; Alves, P.; Sousa-Silva, R.; Monteiro, A.T.; Lomba, A.; Marcos, B.; Honrado, J. Evaluating an unmanned aerial vehicle-based approach for assessing habitat extent and condition in fine-scale early successional mountain mosaics. Appl. Veg. Sci. 2016, 19, 132-146. [CrossRef]

32. Nowack, M.; Dziób, K.; Bogawski, P. Unmanned Aerial Vehicles (UAVs) in environmental biology: A review. Eur. J. Ecol. 2018, 4, 56-74. [CrossRef]

33. Tay, J.Y.L.; Erfmeier, A.; Kalwij, J.M. Reaching new heights: Can drones replace current methods to study plant population dynamics? Plant Ecol. 2018, 219, 1139-1150. [CrossRef]

34. Woellner, R.; Wagner, T.C. Saving species, time and money: Application of unmanned aerial vehicles (UAVs) for monitoring of an endangered alpine river specialist in a small nature reserve. Biol. Conserv. 2019, 233, 162-175. [CrossRef]

35. Rominger, K.; Meyer, S.E. Application of UAV-Based Methodology for Census of an Endangered Plant Species in a Fragile Habitat. Remote Sens. 2019, 11, 719. [CrossRef]

36. Danzi, M.; Di Crescenzo, G.; Ramondini, M.; Santo, A. Use of unmanned aerial vehicles (UAVs) for photogrammetric surveys in rockfall instability studies. Rend. Online Soc. Geol. 2013, 24, 82-85.

37. Mancini, F.; Castagnetti, C.; Rossi, P.; Dubbini, M.; Fazio, L.N.; Perrotti, M.; Lollino, P. An Integrated Procedure to Assess the Stability of Coastal Rocky Cliffs: From UAV Close-Range Photogrammetry to Geomechanical Finite Element Modeling. Remote Sens. 2017, 9, 1235. [CrossRef]

38. Franke, K.W.; Lingwall, B.N.; Zimmaro, P.; Kayen, R.E.; Tommasi, P.; Chiabrando, F.; Santo, A. A Phased reconnaissance approach to documenting landslides following the 2016 Central Italy Earthquakes A Phased reconnaissance approach to documenting landslides following the 2016 Central Italy Earthquakes. Earthq. Spectra 2018, 34, 1693-1719. [CrossRef]

39. Fazio, N.L.; Perrotti, M.; Andriani, G.F.; Mancini, F.; Rossi, P.; Castagnetti, C.; Lollino, P. A new methodological approach to assess the stability of discontinuous rocky cliffs using in-situ surveys supported by UAV-based techniques and 3-D finite element model: A case study. Engineering 2019, 260, 3. [CrossRef]

40. Jaud, M.; Letortu, P.; Théry, C.; Grandjean, P.; Costa, S.; Maquaire, O.; Davidson, R.; Le Dantec, N. UAV survey of a coastal cliff face-Selection of the best imaging angle. Measurement 2019, 139, 10-20. [CrossRef]

41. Strumia, S.; Croce, A.; Santangelo, A. New distributional data of the rare endemic species Eokochia saxicola (Guss.) Freitag and G. Kadereit (Chenopodiaceae): Effects on biogeography and conservation. Plant Biosyst. 2014, 149, 559-564. [CrossRef]

42. Elzinga, C.L.; Salzer, D.W.; Willoughby, J.W. Measuring \& Monitoring Plant Populations; Bureau of Land Management Papers, BLM Technical Reference 1730-1; Bureau of Land Management: Denver, Colorado, 1988.

43. Aronne, G.; De Micco, V.; Santangelo, A.; Santangelo, N.; Santo, A.; Buonanno, M. Coastal vertical cliffs of the National Park of Cilento: Reservoirs of endemic species. In Proceedings of the 7th International Conference on Engineering Mechanics, Structures, Engineering Geology (EMESEG 14), Salerno, Italy, 3-5 June 2014.

44. Pignatti, S. Flora d'Italia; Edagricole: Bologna, Italy, 1982.

45. Blasi, C.; Marignani, M.; Copiz, R.; Fipaldini, M.; Bonacquisti, S.; Del Vico, E.; Rosati, L.; Zavattero, L. Important plant areas in Italy: From data to mapping. Biol. Conserv. 2011, 144, 220-226. [CrossRef]

46. Biondi, E.; Blasi, C. Italian Interpretation Manual of the Habitats (92/43/EEC Directive). Ministero dell'Ambiente e della Tutela del Territorio e del Mare. 2009. Available online: http: //vnr.unipg.it/habitat/ (accessed on 18 December 2019). 
47. Bartolucci, F.; Peruzzi, L.; Galasso, G.; Albano, A.; Alessandrini, A.; Ardenghi, N.M.G.; Astuti, G.; Bacchetta, G.; Ballelli, S.; Banfi, E.; et al. An updated checklist of the vascular flora native to Italy. Plant Biosyst. 2018, 152, 179-303. [CrossRef]

48. Euro+Med (2006-): Euro+Med PlantBase-the Information Resource for Euro-Mediterranean Plant Diversity. Available online: http://ww2.bgbm.org/EuroPlusMed/ (accessed on 11 September 2019).

49. Angelini, P.; Casella, L.; Grignetti, A.; Genovesi, P. Manuali per il Monitoraggio di Specie e Habitat di Interesse Comunitario (Direttiva 92/43/CEE) in Italia: Habitat; ISPRA, Serie Manuali e Linee Guida, 142/2016; Istituto Superiore Per la Ricerca Ambientale: Rome, Italy, 2016.

50. Genovesi, P.; Angelini, P.; Bianchi, E.; Dupré, E.; Ercole, S.; Giacanelli, V.; Ronchi, F.; Stoch, F. Specie e Habitat di Interesse Comunitario in Italia: Distribuzione, Stato di Conservazione e Trend; ISPRA, Serie Rapporti, 194/2014; Istituto Superiore Per la Ricerca Ambientale: Rome, Italy, 2014.

51. Rossi, G.; Montagnani, C.; Gargano, D.; Peruzzi, L.; Abeli, T.; Ravera, S.; Cogoni, A.; Fenu, G.; Magrini, S.; Gennai, M.; et al. Lista Rossa della Flora Italiana. 1. Policy Species e altre Specie Minacciate; Comitato Italiano IUCN e Ministero dell'Ambiente e della Tutela del Territorio e del Mare, Stamperia Romana: Rome, Italy, 2013.

52. Chappuis, E. Crithmum Maritimum. The IUCN Red List of Threatened Species. 2014. Available online: https://www.iucnredlist.org/ (accessed on 18 December 2019).

53. Orsenigo, S.; Montagnani, C.; Fenu, G.; Gargano, D.; Peruzzi, L.; Abeli, T.; Alessandrini, A.; Bacchetta, G.; Bartolucci, F.; Bovio, M.; et al. Red Listing plants under full national responsibility: Extinction risk and threats in the vascular flora endemic to Italy. Biol. Conserv. 2018, 224, 213-222. [CrossRef]

54. US Dept. of Defence. Military Standard-Photographic Lenses (MIL-STD-150A). Section 5.1.1.7, Resolving Power Target. Available online: https://www.techstreet.com/standards/mil-mil-std-150a?product_id=1465242 (accessed on 19 December 2019).

55. Getzin, S.; Wiegand, K.; Schöning, I. Assessing biodiversity in forests using very high-resolution images and unmanned aerial vehicles. Methods Ecol. Evol. 2012, 3, 397-404. [CrossRef]

56. Sokal, R.R.; Rohlf, F.J. Biometry, 3rd ed.; Freeman and Company: New York, NY, USA, 1995.

57. Barone Lumaga, M.R.; Santangelo, A.; Strumia, S. Morpho-functional traits influencing the fitness of highly endangered Eokochia saxicola (Guss.) Freitag \& G. Kadereit (Amaranthaceae). Flora 2015, 218, 11-17. [CrossRef]

58. De Micco, V.; Aronne, G. Occurrence of morphological and anatomical adaptative traits in young and adult plants of the rare Mediterranean cliff species Primula palinuri Petagna. Sci. World J. 2012, 9, 471814. [CrossRef]

59. De Micco, V.; Aronne, G. Morpho-anatomical traits for plant adaptation to drought. In Plant Responses to Drought Stress: From Morphological to Molecular Features; Aroca, R., Ed.; Springer-Verlag: Berlin/Heidelberg, Germany, 2012.

60. Richards, J. Primula; Timber Press: Portland, OR, USA, 2003.

61. Holzschuh, A. Does rock climbing threaten cliff biodiversity? A critical review. Biol. Conserv. 2016, 204, 153-162. [CrossRef]

62. Buonanno, M.; Aronne, G.; Strumia, S.; Danzi, M.; Santo, A.; Santangelo, A. Cliff vegetation monitoring using close range photogrammetry and UAS: Technical issues and practical hints. In Proceedings of the Small Unmanned Aerial Systems for Environmental Research, 5th International Conference, Vila Real, Portugal, 28-30 June 2017.

63. Getzin, S.; Nuske, R.S.; Wiegand, K. Using Unmanned Aerial Vehicles (UAV) to Quantify Spatial Gap Patterns in Forests. Remote Sens. 2014, 6, 6988-7004. [CrossRef]

(C) 2020 by the authors. Licensee MDPI, Basel, Switzerland. This article is an open access article distributed under the terms and conditions of the Creative Commons Attribution (CC BY) license (http://creativecommons.org/licenses/by/4.0/). 